\title{
Reflexão sobre o aprendizado da ciência
}

\author{
Isaias Raw
}

É curioso que nós, professores, centrados em nosso papel e no palco cativo que possuímos, sempre falamos em "ensinar" e raramente pensamos que se trata de "aprender". Quando discutimos ensino de ciências vem sempre à mente toda uma gama de reflexões que vão da escola primária à superior, onde os objetivos são totalmente distintos, variando desde uma motivação para entender o que é, como funciona e qual o impacto da ciência, até o preparo especializado dos futuros cientistas. Para mim, talvez a única forma de tentar articular coerentemente esse universo, é rever criticamente os longos anos em que, na direção do IBECC, FUNBEC e Fundação Carlos Chagas, procurei contribuir para a sua inovação.

Procuro lembrar o que me motivou, em 1949, a pedir uma reunião especial da SBPC para discutir esse assunto. Naquela ocasião eu era aluno da Faculdade de Medicina, dava aulas num colégio e iniciava meus primeiros passos na investigação. Mesmo naquele importante centro senti a pobreza do nosso meio científico. Estava claro que o País de-. mandava mais e melhores pesquisadores. Sugeri que para formar os futuros cientistas era importante inovar o ensino de ciências na escola secundária, dando ao jovem a oportunidade de chegar às suas próprias conclusões por meio de experiências imaginativas, substituindo os embolorados laboratórios importados da Europa, e jamais usados, por equipamentos simples, de baixo custo e que permitissem realizar experiências, fazer observações, errar e acertar. A outra iniciativa que sugeri foi a de provocar interesse pela ciência, dando a oportunidade a todos, até mesmo àqueles que não fossem seguir carreiras cientificas ou tecnológicas, para compreender o que é ciência e como o cientista, parte integrante de uma comunidade internacional, atua. A reunião foi um relativo sucesso mas, de acordo com a tradição de nossa cultura, caberia ao governo (sempre o governo) agir...

\section{MUSEUS, FEIRAS E CONCURSOS}

A Lei de Bases e Diretrizes não havia sido sequer imaginada. O ensino era uniforme em todas as escolas. Todos os livros tinham o mesmo índice: o programa oficial. Inovar era proibido! Estávamos em "boa" companhia, com a França ou a Espanha, onde a autoridade para rever o currículo emanava do Vaticano.

O único espaço existente para inovar era extra-escolar. Uma vez que a SBPC não tinha condições de executar, fui procurar uma instituição "guarda-chuva" para agir. Havia um organismo do Ministério de Relações Exteriores, o IBECC, Instituto Brasileiro para Educação, Ciência e Cultura, que deveria executar no País atividades em cooperação com a UNESCO. A seção de São Paulo, como única atividade, se limitava a reuniōes esporádicas, coincidentemente no Departamento de Bioquímica da Faculdade de Medicina. Tínhamos encontrado um bom guarda-chuva para lançar programas que estimulassem o interesse dos jovens e fomos procurar recursos.
ISAIAS RAW é professor aposentado da Faculdade de Medicina da USP e, atualmente, é diretor do Centro de Biotecnologia do Instituto Butantã.

Agradeço os comentários dos professores Walter Colli e Myriam Krasilchik, dois es. timados colaboradores de táo longa jor. nada.
Dezembro

Janeiro

Fevereiro 1990-1991

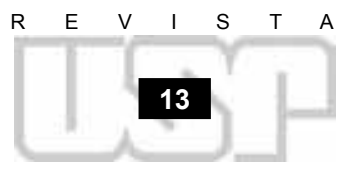


$\mathrm{Na}$ época o interesse por energia atômica era grande. Conseguimos na prefeitura recursos para montar uma exposição que tinha, além dos painéis didáticos, uma série de experiências reais e modelos animados. Essa exposição atraiu cerca de cinqüenta mil pessoas, na grande maioria jovens - lembremos que São Paulo não tinha sequer dois milhões de habitantes em 1952. O sucesso fez com que a exposição fosse levada pela UNESCO para outros países do continente. A exposição seria seguida de outras mais, transformando a galeria Prestes Maia, então o coração da cidade, num Museu de Ciência. Não conseguimos recursos para continuar. Em 1954, após a exposição do IV Centenário de São Paulo, conseguimos organizar uma sociedade civil que montaria num dos prédios do Ibirapuera o Museu de Ciências da Cidade. Uma disputa por cargos e prestígios pessoais matou o museu. Voltamos a tentar, nos anos 60 , quando o IBECC montou uma exposição na Bienal, uma câmara escura onde funcionavam experiências e modelos em torno da natureza da luz. Finalmente nos anos 80 , esta idéia parece ter vingado quando, por iniciativa do CNPq, surgiu a Estação Ciência.

O ex-Secretário de Cultura da Prefeitura, que havia financiado a exposição do átomo, foi quem deu apoio, através de uma empresa de seguros, a outra iniciativa: o concurso Cientistas de Amanhã. A idéia básica, uma modificação do "Talent Search" americano, era selecionar jovens estudantes do secundário que haviam realizado uma pequena investigação original. Os dez melhores eram selecionados e levados para a reunião anual da SBPC onde encontrariam, num dos cientistas presentes, um orientador para sua carreira. Os três melhores eram apresentados num programa de televisão em horário nobre. Ao mesmo tempo era premiado um professor secundário pela sua atividade inovadora no ensino das ciências.

A terceira iniciativa que lançamos nos anos $\mathbf{5 0}$ foram as Feiras de Ciências, onde esperávamos reunir jovens que fizessem demonstrações de suas experiências a outros jovens. A idéia teve uma grande aceitação e, de novo, a galeria Prestes Maia se encheu de cavaletes, estudantes e professores. A idéia foi levada a Porto Alegre e se espalhou pelo País.

A quarta iniciativa foi criar os Clubes de Ciência. No quarto andar da Faculdade de Medicina conseguimos uma sala, aparelhos do extinto pré-médico, algumas ferramentas e até um torno a pedal. Jovens vinham ao Clube para realizar experiências.

A outra iniciativa foi utilizar a televisão. Consegui um programa de alguns minutos na Tupi, aos domingos, na hora do almoço, para realizar experiências de impacto visual e que duravam apenas alguns minutos. Algumas poderiam ser facilmente repetidas e o foram (como a lata com água fervendo que, fechada e esfriada, colabava sob a pressão atmosférica). As experiências eram explicadas no programa seguinte, dando aos jovens a oportunidade de pensar, pesquisar o assunto, e até repetir para encontrar a explicação. Uma vez pedi a um colega de faculdade para demonstrar um coração de sapo em perfusão que ficou pulsando horas - toda a programação parou e São Paulo ficou vendo o coração isolado funcionar. Como tudo era improvisado, às vezes havia falhas, mas o interesse manteve-se e por mais de um ano o programa continuou no ar apresentado por um ator (que era químico).

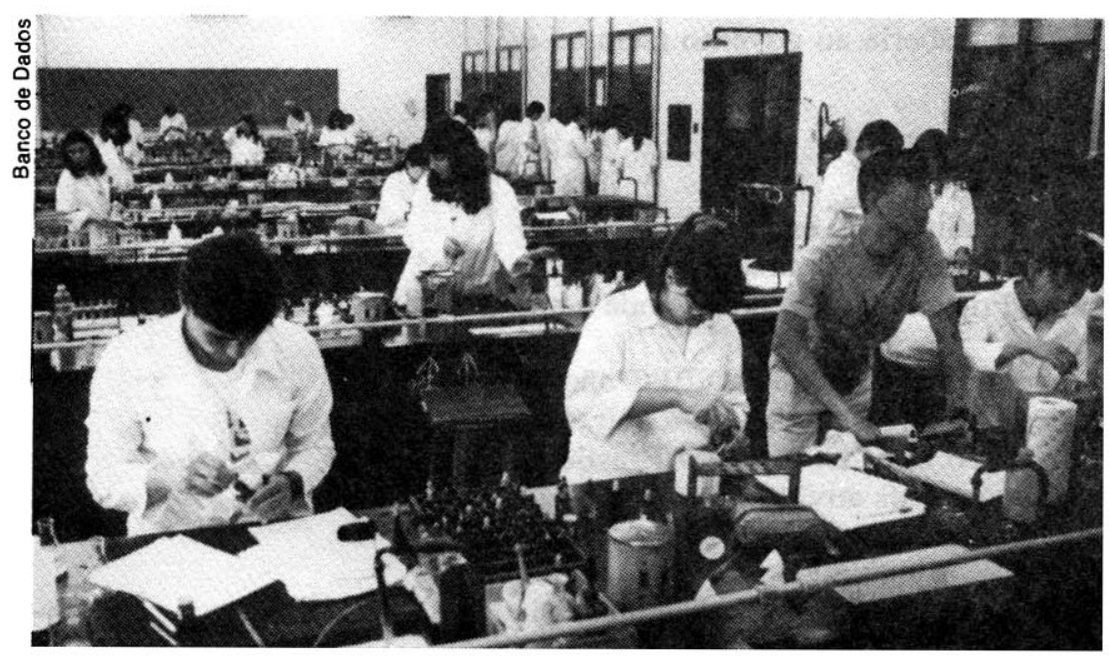

Decorridas quase quatro décadas ê fácil observar o lado positivo e as limitaçōes dessas iniciativas. Isso é particularmente importante, agora que essas idéias estão sendo reinventadas sem que se tenha presente a sua limitada importância. Museus de Ciência de altíssimo nível existem nas principais cidades do primeiro mundo. Os mais famosos são o Palais de Decouverte em $\mathrm{Pa}$ ris, o Museu de História Natural de Nova York e os Museus de Ciência e Tecnologia de Chicago e Washington. São tão famosos quanto o Louvre, a Galeria Nacional de Washington, o Metropolitan ou o Prado. Despertam interesse para os já motivados. Atraem milhões que os percorrem em passo acelerado, parando aqui e acolá - turistas "que fazem o Louvre inteiro" em uma tarde! O Palais coexistiu com a decadência do 
ensino e da ciência francesa. Tais museus têm algum impacto, mas não são os meios mais eficientes para motivar aqueles que serão os futuros cientistas. $\mathrm{O}$ efeito sobre as massas é transitório e, como discutirei adiante, periférico. Exposições menores, com um tópico limitado, adequadamente apresentadas, que permitam ao visitante operar ainda que por controle remoto (como no Museu de Chicago ou no Exploratorium de São Francisco), são muitas vezes mais eficientes do que uma miscelânea de coisas toscas improvisadas ou painéis comerciais.

As feiras de ciências foram rapidamente deturpadas. Ao invés de trazer experimentos, as feiras tornaram-se um amontoado de figuras desenhadas em cartolina e modelos de isopor, expostas por estudantes que não demonstram nenhuma vivência do que pesquisaram. Um grande "oba-oba", onde ciência e pseudociência se misturam, como uma contribuição negligente para o aprendizado real da ciência.

O concurso Cientistas de Amanhã inicialmente identificou alguns jovens extraordinários e que hoje são pesquisadores nas principais universidades. Todavia o aparato de dar prêmios, levá-los à televisão e apresentá-los como gênios, contribuiu para deturpar sua visão de como é realmente ser cientista e não raro criou, para cada um dos premiados, uma expectativa difícil de enfrentar. Tentei corrigir esses defeitos lançando o congresso Jovens Cientistas, uma réplica das reuniões da SBPC, onde estudantes selecionados pelo trabalho apresentado eram levados para um pequeno congresso, tendo cientistas presentes para orientar as discussões e onde não haveria prêmios nem os jovens seriam apresentados como gênios. $O$ esforço de dar aos estudantes uma visão de como era de fato uma reunião científica não frutificou e, graças à tradição, o concurso Cientistas de Amanhã manteve sua estrutura inicial, apesar de ter perdido a pompa da entrega de prêmios na televisão. Recentemente vi o concurso replicado como parte do programa Ciranda da Ciência. Os organizadores, encurralados na estrutura que os obriga a selecionar jovens de muitos estados, repetem uma mistura de concurso e feira. Com grande publicidade são aplaudidos os selecionados e, os melhores, premiados. Visitando as exposições dos trabalhos fiquei estarrecido ao ver que alguém possa imaginar que o futuro da ciência brasileira resida num jovem que, tendo montado uma maqueta, contendo um recipiente plástico ligado a um tubo, num monte de gesso, imagina ter contribuído para mostrar como o Nordeste pode se livrar da seca!

O Clube de Ciências foi por nós abandonado, pois poderíamos atender, no máximo, a duas dezenas de jovens, um esforço inútil frente ao tamanho do problema da educação nacional. Sua multiplicação ocorreu em alguns lugares onde havia um professor excepcional. Todavia, como percebemos pela busca dos raros professores para premiar nos concursos, pouco poderíamos fazer para multiplicá-los.

A televisão brasileira evoluiu muito desde os tempos da Tupi. É impressionante ver a qualidade dos filmes que vêm sendo produzidos em ciências. São aulas muito didáticas e bem ilustradas mas estéreis e aborrecidas. Procuram transmitir passivamente as informações e não apelam para mais do que a simples memorização.

\section{OS KITS}

A idéia que me perseguia era poder oferecer aos jovens um pequeno laboratório que pudessem usar em casa. É preciso entender que até os anos 60 , quando a indústria brasileira era ainda incipiente, as escolas tinham "laboratórios" onde em elaboradas caixas de madeira estavam equipamentos e materiais importados. Ao lado do brilho dos suportes cromados estava até a água destilada importada da Europa. Eram equipamentos que haviam sido projetados para demonstrações, jamais para serem tocados. Garantiam que a experiência sempre saísse certinha. Apesar disso, os raros professores que os utilizavam freqüentemente iniciavam a demonstração com uma desculpa: se não desse certo a culpa era do equipamento, pois o compêndio trazia a absoluta verdade cientifica. Era como uma religião. Uma pequena indústria nacional tentava competir e como sabia

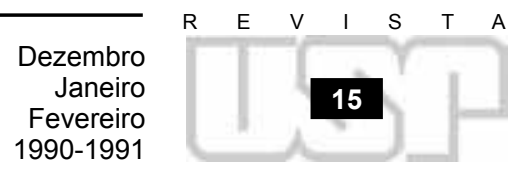


que os aparelhos jamais seriam usados construía espectroscópios sem prisma...

Imaginei, então, produzir pequenos laboratórios. $O$ de química foi o primeiro, seguido de outros de biologia e física. Cada "laboratório" estava acondicionado numa maleta que também servia de mesa. Para orientar os jovens, transformei a revista Cultus (uma revista de ensino de ciências que lancei em 1949) em três jornais - química, física e biologia - aos quais se juntou depois um de computação (na década de 50). Os jovens que comprassem os laboratórios teriam direito a uma assinatura, começando sempre pelo primeiro número.

Uma pequena oficina foi montada na Faculdade de Medicina para produzir os kits e, em pouco tempo, tínhamos centenas de jovens fazendo experiências em casa. Mais importante, como se esperava, eles passariam a levar o kit para a escola e reptariam os seus professores. Estava quebrado o mais importante tabu: era possível dar aos jovens, com recursos módicos, sem importar equipamentos, condições para realizar experiências.

Imaginamos, para torná-los mais acessíveis, reduzir o custo dos "laboratórios" substituindo-os por pequenas unidades, os kits. Isso permitiu aos jovens adquirir novos kits à medida do seu interesse. Os "jornais" foram substituídos por folhetos em cada kit. Esses kits de baixo custo começaram a ser produzidos pelo IBECC. Quando mudamos da Faculdade de Medicina para a Cidade Universitária, abrimos uma loja, que até hoje atende aos jovens que querem kits, peças, reagentes e tubos de ensaio.

Mas São Paulo não era o Brasil e era preciso encontrar uma forma de colocar os kits ao alcance da população nacional. Tentamos várias vezes colocá-los em lojas de brinquedos (que até hoje se denominam educativas) ou nas lojas que distribuem os cadernos e livros do MEC, mas pouco logramos. Esta idéia finalmente deslanchou, em 1969, quando eu já estava exilado no exterior e os professores que trabalharam comigo na FUNBEC conseguiram produzir kits muito originais e inovadores que foram desenvolvidos e fabricados pela Editora Abril. Cada kit era centrado num famoso cientista que a cada duas semanas aparecia nas bancas de jornal. O sucesso foi estrondoso: o primeiro vendeu 250.000 exemplares e 50.000 famńlias compraram todos os 50 kits. Constituiuse em uma escola fora da escola e, pela mão dos alunos, atingiu também as escolas. A própria Universidade Aberta inglesa recomendou os kits para um projeto internacional. Todavia, pela sua natureza, a série era finita, e, com o número 50, a iniciativa morreu. Ao voltar ao Brasil tentei várias vezes revivê-la sem sucesso: a iniciativa privada, que havia tido um lucro considerável, não estava preparada para arriscar seu capital. Apesar do fabuloso impacto (até hoje encontro jovens professores e pesquisadores que ainda têm em casa o que restou daqueles kits) a idéia não foi reeditada ou reinventada. O programa do PADCT (CAPES com apoio financeiro do BIRD) sequer a considerou. Imagine-se o potencial da combinação dos kits com a televisão!

\section{ENTRANDO NAS ESCOLAS}

O desenvolvimento dos kits permitiu criar uma equipe de professores secundários especializados, que desenvolveram com criatividade novas experiências usando materiais simples, e permitindo aos jovens realizá-las sem que soubessem antecipadamente dos resultados. Levados às escolas pelos alunos que, naturalmente, questionam seus professores, os kits abriram caminho para levar uma atividade de experimentação científica, de custo aceitável, para as escolas secundárias.

Era o momento de tentar interferir no sistema educacional formal. Visitas, que se repetiram a cada mês com os professores Anísio Teixeira, então diretor do INEP e CAPES, e com o professor Gildásio Amado, diretor do ensino secundário do MEC, fizeram-nos compreender o alcance das propostas. Anísio encomendou kits para os centros regionais como o CRUSP, onde se retreinavam professores das escolas normais, e Gildásio iniciou a distribuição de kits para escolas secundárias oficiais. Estava encontrada uma forma de subverter o ensino de ciências, inovando sem propor reformas que nunca passam de reordenamento dos mesmos tópicos. Tais reformas terminam por passar o conhecimento do giz e do quadro negro para os cadernos, sem deixar na cabeça mais do que alguma terminologia (quantos dos mais velhos lembram-se de palavras como fanerogamas, calorimetria ou cátions, que jamais voltaram a usar?). Esta é provavelmente uma importante lição de um passado esquecido: a inovação do ensino, em qualquer nível, não é feita nos gabinetes do MEC ou nos Conselhos mas pela intervenção da liderança intelectual. 


\section{A INOVAÇão e o PAPEl das UNIVERSIDAdes}

O programa de kits colocou o IBECC no mapa. O interesse pela experimentação como parte essencial do ensino de ciências cresceu. Era o momento de inovar o conteúdo, cristalizado há muitas décadas numa visão estreita do que seria fundamental aprender. Biologia se perdia na descrição de folhas serreadas ou lisas e na classificação das esponjas. Na química os alunos imaginavam que com alguns tubos de ensaio e um pouco de gás sulfídrico poderiam identificar qualquer composto, e a física se perdia nas máquinas simples e problemas de elevadores imaginários sem atrito. A ciência parecia completa e estática desde o fim do século XVIII.

Começamos a trabalhar na criação de novos textos, onde a redescoberta através de experiências simples estava neles embutida. O primeiro projeto foi a Iniciação à Ciência, onde, sem o formalismo e a visão deturpada daqueles que não pesquisam e imaginam saber como funciona a investigação científica, os estudantes começam a fazer experiências e tirar conclusōes. Foi como traduzimos a proposta do famoso químico (e interventor na Alemanha pós-guerra) Connant descrita como "táticas e estratégia das ciências". Obviamente editá-lo era um risco econômico, pois não se sabia se haveria mercado. A Editora da USP, que eu havia fundado não para competir com as editoras comerciais (ou para, como ocorreu por muitos anos, subsidiá-las), estava agora em mãos mais conservadoras. Fui então à Universidade de Brasília onde organizamos a editora que passou a editar os projetos inovadores.

A introdução desse e de outros projetos inovadores exigia uma ação concertada para produzir ao mesmo tempo o texto, os materiais necessários para que os estudantes realizassem as experiências e treinar os professores. O texto, a Editora da UnB produziu. Havia alguns visionários que imaginavam utilizar até o lixo para ensinar ciências. $O$ professor, que mal tem tempo para preparar suas aulas, ou ler provas dos alunos, deveria ainda coletar copos, garrafas e outros materiais para suas classes! Era obvio que isso não iria ou irá ocorrer, nem é mais econômico. O IBECC passou a produzir os equipamentos de baixo custo para as escolas, fornecendo todo o material necessário.

O terceiro componente era a atualização dos professores em exercício e a preparação dos futuros professores, treinamento que não deveria ser genérico mas que teria de incluir especificamente os novos materiais produzidos. Como se tratava do ensino médio, a tarefa cabia naturalmente às universidades. Conseguimos persuadir o MEC a implantar centros de treinamento junto às universidades de Pernambuco, Rio Grande do Sul e Minas Gerais. Em São Paulo junto ao IBECC foi criado o CECISP. No Rio, o movimento inovador de ensino de ciências estava fora da universidade, curiosamente liderado por alguns médicos, que passaram a constituir o Centro de Treinamento do Rio.

Estava implantada uma estratégia de inovação que incluía a íntima cooperação entre a liderança científica, que compreendia o que se fazia em ciência, como se fazia e para onde iria esta ciência, com uma elite selecionada de professores secundários, capazes de traduzir a idéia em livros, kits e treinamento a fim de lograr a inovação. Subvertemos não apenas as escolas médias, mas a própria universidade, envolvendo-a naquilo que não assumia: o seu papel na formação de seus futuros alunos e no retreinamento dos professores que produziu.

\section{INOVAÇÃo do ENSINO DE CIÊNCIAS, UMA PRIORIDADE NACIONAL}

O ensino de ciências não andava melhor no primeiro mundo. Os Ministérios de Educação não tinham sequer compreensão do problema. A eficiência do processo educacional é medida pelas reprovaçōes em provas que testam simplesmente a memorização do conteúdo ensinado. Esta forma de pensar, que tinha ampla aceitação no Brasil, era dos que achavam que o importante era ensinar bem, independentemente do que os alunos aprendessem, e desvinculada da capacidade de pensar e resolver problemas, dos avanços da ciência e de seu impacto crescente na sociedade contemporânea.

Nos Estados Unidos levantou-se a voz do prof. Jerold Zacharias, do MIT, recém-saído do projeto Manhatan que o obrigou a entender como se implanta e administra um projeto nacional. Ele se aproveitou do lançamento do sputnik para mobilizar o interesse e os recursos do governo a fim de inovar o ensino das ciências, essencial à formação do quadro de futuros pesquisadores, sem o qual os Estados Unidos seriam tecnologicamente superados. Atuar em milhares de escolas, afirmou Zacharias, demandaria preparar novos textos, inovando radicalmente o conteúdo e a visão da ciência, que não havia

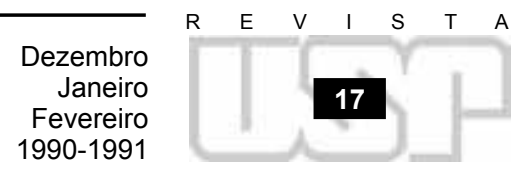


estacionado e que não poderia ser atualizada simplesmente adicionando aos livros um último capítulo sobre energia atômica. Para aprender a pensar cientificamente, os jovens deveriam realizar experiências não como uma eventual confirmação do que estava no texto e, para isso, poderiam empregar materiais simples, de baixo custo, mas inteligentes. Para que os professores pudessem ensinar os novos textos e práticas de laboratórios deveriam ser retreinados. Isso era bastante familiar para nós no IBECC...

Minha visita ao MIT fez-me sentir um pigmeu (nunca imaginaria que, anos mais tarde, eu mesmo estaria dirigindo projetos de ensino de ciências naquela instituição). As dimensões do problema no Brasil não eram muito menores do que nos Estados Unidos. Contávamos com pequenos recursos. O MEC era nosso principal comprador ressarcindo os custos dos materiais fornecidos. A Secretaria da Educação do Estado de São Paulo comissionava professores, e a USP nos cedia um galpão. Os investimentos e as próprias máquinas para produzir os kits derivaram de importantes doações das Fundações Rockefeller e Ford. A Fundação Rockefeller me havia dado um auxflio de $\mathbf{4 5 . 0 0 0}$ dólares, e

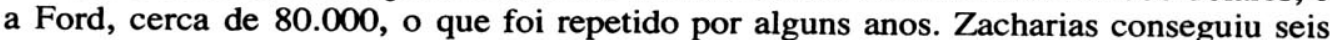
milhôes de dólares para o projeto de física denominado PSSC. Mas a imensa diferença entre eles e nós era a massa cinzenta de que dispunham para desenvolver o projeto. Decidi trazer o PSSC para o Brasil.

Logo em seguida, a National Science Foundation financiava um grupo de biologia a desenvolver três projetos, dois grupos de química e um de matemática. Quando os vários grupos se reuniram para discutir suas atividades, fui como convidado especial. Em pouco tempo o IBECC estava participando através de algumas lideranças selecionadas que trariam os projetos para o Brasil (Myriam Krasilchik teve participação importante nos projetos de biologia, Pierre Luci e Antonio Teixeira no PSSC e Ernesto Giesbrecht no CBA). O Brasil passou a ser o primeiro pars a utilizar significativamente esses projetos. Myriam imediatamente produziu, como parte da chamada versão "verde", um volume de ecologia para escolas (idéia recém-redescoberta pelo próprio presidente Collor). Os equipamentos foram fabricados. A Organização Panamericana, impressionada com o IBECC, financiou os cursos de treinamento para cerca de quatrocentos líderes, o que envolveu, além dos brasileiros, professores (na maioria universitários) de todos os paŕses latino-americanos, e organizou conferências sobre a inovação do ensino em física, química e biologia, convidando-me a participar em cada uma delas. A UNESCO e a IUPAC patrocinaram outras tantas conferências internacionais.

O impacto dessas inovações é fácil de detectar mesmo após tantos anos. Bastaria

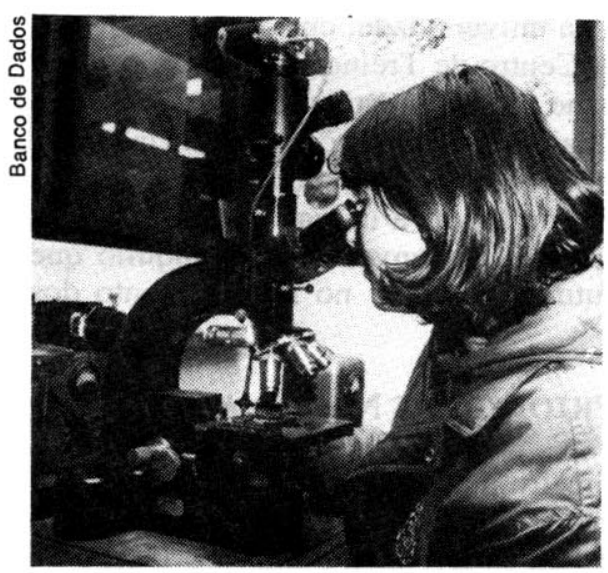
confrontar os vestibulares até 60 , e depois desses, onde aparecem conceitos-chave jamais imaginados para a escola secundária (metabolismo intermediário, estrutura do DNA, ligações covalentes, entropia e dualidade luz-onda são apenas alguns exemplos).

O impacto internacional desses projetos foi incrivel. Versões do PSSC apareceram em todas as línguas. Finalmente, a Inglaterra resolveu seguir o exemplo e mandou buscar um inglês, o prof. Eric Rogers que ensinava em Princeton, para dirigir o projeto de física financiado pela Nufield, ao qual se somaram projetos em biologia e química. Os três davam muita ênfase à experimentação em laboratório, ainda que fossem menos inovadores que os projetos norte-americanos. $\mathrm{O}$ impacto dos projetos americanos e ingleses no resto do mundo, pela sua sofisticação, de certa forma inibiu outras iniciativas.

Essa imensa experiência foi, entretanto, perdendo a força. É verdade que livros comerciais foram incorporando muitos dos conceitos que substituŕram o velho conteúdo. $\mathrm{O}$ uso do laboratório foi caindo. Talvez o fator mais importante nos Estados Unidos seja o fato dos estudantes poderem escolher apenas um curso de ciências e, freqüentemente, ficarem com biologia que lhes parece mais fácil. PSSC e CBA (liderado pelo famoso químico Pimentel que descobriu o maser) eram difíceis para a grande massa. Os grandes conceitos abstratos não são fáceis para o estudante comum e estes cursos aca- 
baram influenciando o ensino, não na escola secundária, mas na superior.

Até o processo de inovar, envolvendo a liderança científica de um Zacharias ou de um Pimentel, a preparação de um texto, dos materiais e guias de laboratório, oferecendo cursos de treinamento e guias de professor, foram sendo esquecidos. Voltamos ao ridículo de imaginar que cada modesto professor de pequeno colégio irá criar sozinho novos projetos curriculares, como se inovar fosse o mesmo que escrever em casa uma apostila ao alcance de qualquer professor secundário.

Até hoje esses projetos, por sua sofisticação, nunca foram ultrapassados. Seu maior defeito foi o nível, incompatível com a escola secundária norte-americana, mas não com a brasileira quando apenas uma elite chegava ao secundário. Além da profunda inovação concepcional, esses projetos trouxeram uma inovação na estratégia de implantação. Acredito que acertei em trazê-los para o Brasil, com uma única exceção, o curso de matemática moderna SMSG. Cassado que fui, no dia que voltei ao Brasil, depois de onze anos, ouvi no rádio do carro um programa em todas as estações, onde se descrevia a teoria dos conjuntos, com "setas" de A para B, ridiculamente apresentadas por rádio e que soavam como se fossem feitas de aço. Havíamos municiado o sistema escolar com um produto dirigido a uma minoria e que estava distorcendo a educação matemática da maioria, permitindo criar outra "Hora do Brasil" inútil.

\section{O Vestibular Como ARma de InOVAÇÃo}

A sociedade investe na universidade como um centro de criação intelectual e para formar os profissionais de que necessita. Ao pagar pela formação desses profissionais, ela espera que a universidade os produza em nível e em número adequado à demanda, oferecendo suas vagas aos mais capazes de atingir essa competência. Naturalmente deve selecionar os candidatos, escolhendo os que têm maior potencial e, num estado democrático, o acesso deve estar aberto a todos. Com raras e importantes exceções, o potencial adquirido pelo jovem depende não apenas de fatores intrínsecos (inteligência, motivação, dedicação, interesse) mas de fatores extrínsecos que incluem a atmosfera e o incentivo que o jovem teve em casa e na escola. Praticamente qualquer critério seleciona razoavelmente os mais capazes. Todavia, é extremamente difícil classificar aqueles um pouco menos capazes, garantindo que o investimento da sociedade seja dado rigorosamente pela competência.

Quando fui escolhido para organizar o vestibular da Faculdade de Medicina, estava preocupado em implantar um processo de seleção o mais objetivo possível, e evitar o trauma psicológico e financeiro imposto por repetidos vestibulares isolados (que voltam a ocorrer até para as três universidades do Estado de São Paulo). Mas havia um aspecto que me preocupava particularmente: o impacto inconsciente e inconseqüente dos vestibulares no ensino médio, impacto que se estende a todos, inclusive àqueles que não irão freqüentar curso superior. Esse impacto é assimilado pelos cursinhos mas deturpa a escola secundária. Resolvi agir exatamente ao contrário, usando o vestibular como arma para impor ao secundário as inovações pretendidas. Havia uma intensa interação entre o IBECC (e a FUNBEC que o substituiu) e a Fundação Carlos Chagas. Conseguimos muito mais do que os programas oficiais do MEC antes de Bases e Diretrizes, da mesma forma que hoje a universidade consegue impor a todos que leiam determinados livros. $\mathrm{O}$ ponto positivo foi fazer com que todos os alunos após a seleção prévia em provas, passassem por um exame de laboratório em física, química e biologia. Foi fundamental comparar os resultados das provas, mostrando que alunos que eram capazes de resolver um problema de circuitos elétricos complicados eram incapazes de medir a voltagem de uma bateria, evidenciando que realmente não haviam aprendido...

\section{MÁQUiNAS E COMPUTADORES}

Em 1964 a relação entre o IBECC e a UNESCO se inverteu. O IBECC utilizou o nome da UNESCO para deslanchar seu programa de inovação. O prestígio passou fronteiras e voltava agora a UNESCO, interessada em produzir os pacotes educacionais, a buscar o IBECC, para iniciar um projeto de física, utilizando como tema central a natureza da luz. De novo a idéia era produzir textos, kits, filmes curtos, mas até a última hora não se sabia que com esse projeto, devido à fonte dos recursos, estava sendo imposto o uso do ensino programado. Por essa técnica, o texto deveria ser dividido em pequenos passos, de forma que a grande maioria dos estudantes, sem qualquer imagina-

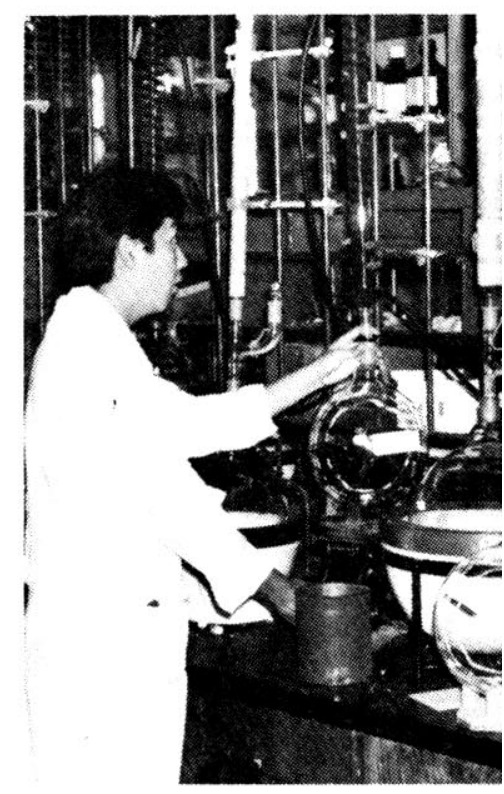

西

(1)

.

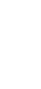

.


ção ou esforço mais do que de memorização, estivesse sempre certa. No ano anterior Zacharias me havia convidado para uma reunião promovida pela presidência dos Estados Unidos para discutir inovação nos colleges. Essa reunião teve lugar na Tufts University, num prédio onde havia um museu de máquinas de ensinar obsoletas, todas para utilizar ensino programado. O projeto da UNESCO trouxe participantes europeus e latino-americanos e conseguiu produzir kits com experiências inéditas e alguns filmes. Foi uma experiência válida apesar do texto ser ensino programado. Como não era um curso completo, caiu no esquecimento sem maior impacto no Brasil ou fora dele.

Há alguns anos recebi um convite para participar da comissão do MEC para uso educacional de computadores. Num paŕs onde ainda existe um número grande de crianças sem escola e de escolas sem giz e quadro-negro, ou mesmo carteiras (e alguns acham que a solução é inovar implantando-se um quadro-negro que tira xerox), achei melhor aceitar, muito mais para dizer muitos "não". Indiscutivelmente o computador está aŕ para ficar, e saber usá-lo (e, para parte dos estudantes, compreender como funciona) é fundamental. Todavia, imaginar que o computador substitui o livro e, sobretudo, o laboratório, e que, através dele se pode aprender ciências está por ser ainda demonstrado. E foi por isso que naquela comissão me empenhei para criar os centros de computação que permitissem aos jovens aprender a manejar os computadores enquanto se procura inventar meios de usá-los criativamente para o ensino das ciências.

É chocante o contraste de algumas iniciativas da educação informal com a ineficiência da escola formal. Para isso basta comparar a eficiência da escola de inglês da esquina com o colégio e até com a universidade. Há muitas décadas, a Remington, que fabricava máquinas de escrever, para estimular as vendas criou as escolas de datilografia. Numa sala cheia de máquinas, com apenas uma atendente, o estudante que marca sua meia hora abre o caderno e copia até aprender. As máquinas eram usadas doze horas por dia e substituídas quando gastas. O retorno do capital é maximizado. Essa foi a idéia transmitida para os centros de computação instalados em vários estados, onde foram alocados pela Comissão de Informática do MEC, da qual participei, cerca de oitocentos micros. Imagine-se a mesma idéia aplicada a centros especiais para ensino de ciências que podem atender centenas de estudantes por dia.

\section{INOVANDO A UNIVERSIDADE}

Inovar o ensino superior é uma tarefa igualmente importante e, politicamente, quase impossível. Na minha faculdade havia trinta cátedras, aŕ inclứdas três de clínica e três de cirurgia. O currículo era aprovado anualmente por um acordo de cavalheiros. Discutir era invadir o quintal do vizinho. Até 1964, o catedrático, entre os quais me incluo, era imperador absoluto da área de conhecimento, decidia sobre o ensino e sobre a existência ou não da pesquisa. Inovar em minha cátedra, dentro da carga horária prevista, com os meus assistentes, era minha prerrogativa. Essa incluía bioquímica, biofísica, e acabei incluindo genética, que paradoxalmente inexistia como disciplina na Faculdade de Medicina, até os anos 60 . Nossos alunos eram muito bem selecionados e pudemos fazer uma inovação profunda: os alunos recebiam uma orientação mensal e estudavam sozinhos, tirando suas dúvidas em pequenos grupos, quando realizavam também experiências. Das 160 aulas teóricas eliminamos 152 sem problema. O tempo gasto no departamento passou a ser para aprender e não para ouvir um professor ensinando.

Uma inovação mais profunda foi possível em 1963 com a criação do curso experimental de medicina. Ao invés de ceder à pressão dos candidatos excedentes criando mais uma faculdade de medicina ou um aumento indiscriminado de vagas, tomamos a oportunidade para inovar. Era preciso rever o tempo dispendido com informações morfológicas e abrir espaço para os grandes avanços da bioquímica e da genética que mais tarde desembocaram na biologia molecular. Para abrir esse espaço era preciso eliminar a repetição não-inteligente, pois a maioria das cadeiras básicas repetia os mesmos conceitos, em níveis de atualização e profundidade diferentes. Era preciso integrar os conhecimentos, uma tarefa que o corpo docente não sabia como fazer, mas esperava que os alunos o fizessem. Esta integração era impossível num curso fracionado entre cadeiras e catedráticos. Era também importante integrar o curso fundamental com o curso profissional, clínico; não apenas com a medicina privada e hospitalar, mas com a medicina social e preventiva. A oportunidade surgiu em outubro, e em março o curso já estava funcionando. Imediatamente o curso experimental passou a ser a primeira escolha dos candidatos à medicina, e o produto da experiência e da criatividade nascidas na Ca- 
sa de Arnaldo passou a ser o filho bastardo que teria um dia que ser extinto.

A experiência com o ensino de ciências na escola secundária já havia demonstrado que é impossível inovar sem recriar livros, cursos de laboratório e exames. O que hoje imaginamos ser a estrutura tradicional de uma disciplina foi o impacto de um livro. Não existiu um curso de física antes de Ganot e ainda hoje imperam Sears e seus seguidores. Fisiologia foi inventada por Best e Taylor, farmacologia por Goodman e Gilman, biologia molecular por Watson. Os exercícios de escrever novos currículos, e até os esforços de escrever longas listas de objetivos educacionais jamais resultaram numa inovação, apenas se seguiram a ela.

Uma de minhas atividades no Centro de Pesquisas Educacionais do MIT foi colocar num texto o modelo que havia pensado para o curso experimental de medicina da USP e antes para o curso médico da UnB, onde desapareceriam as disciplinas tradicionais e artificiais do passado, substituídas por um conjunto integrado de conhecimentos desenvolvidos em torno de um centro de interesse que, para estudantes de medicina, era uma doença ou síndrome. O projeto, que recebeu apoio do MIT e da Organização Pan-Americana de Saúde e, em seguida, da Escola de Saúde Pública da Harvard, onde fui trabalhar, resultou na publicação de um modelo (em inglês). Recentemente tenho me dedicado a construir esses modelos que constituirão uma série (As bases moleculares da Medicina) cujo volume I será publicado com a cooperação da Editora da USP.

É fundamental fazer um esforço contínuo para inovar. A idéia de um curso experimental fornece uma estrutura que permite experimentar novas idéias. Eu defenderia que o papel da USP no ensino de graduação deveria ser mais limitado, sobretudo em áreas não técnico-científicas, onde a escola privada preenche parte das necessidades. A USP deveria ser um campo de constantes inovações, criando novos modelos e repassando-os para outras universidades. Ao lado disso manteria seu papel como o principal centro de pós-graduação e pesquisa.

Nem todas as inovações podem e devem ser tão radicais como a do curso experimental, que pretendia rever toda a formação do futuro médico. Tomemos o ensino da física, que é ministrado a estudantes com as mais variadas opções profissionais. O PSSC trouxe como ponto central para a física a dualidade onda-partícula, revendo o que, no limiar do século XXI, é entender física. Todavia não me parece que esta seja a física que melhor prepara o estudante que se dirige à tecnologia. Muitas vezes tentei catalisar o desenvolvimento de um projeto que centrasse a física em propriedades dos materiais e que poderia ser melhor articulado com um curso básico de química. Um esforço dessa natureza ainda está por surgir e terá um amplo mercado internacional. $\mathrm{O}$ mesmo ocorreria se criássemos novos cursos de biologia, que substituíssem o já velho BSCS com suas versões ecológica, genética e bioquímica. Os novos focos de interesse são ainda ecologia e, além de genética e bioquímica, biotecnologia. Esses novos projetos encontrariam uso nos cursos de formação de professores e, ao mesmo tempo, poderiam ser introduzidos nas melhores escolas secundárias.

\section{AMPLIANDO O PAPEL DA UNIVERSIDADE}

Procuro não agir como o velho e repetir "no meu tempo os alunos eram melhores"... A abertura das escolas superiores para uma grande massa de alunos era prevista (e no Estado de São Paulo a semeamos quando, na gestão do prof. Ulhoa Cintra na Secretaria da Educação, foram modificados os exames de admissão que, até aquele momento, negavam escola para a grande maioria, quando a nossa Constituição dizia que o ensino era público, gratuito e universal até quatorze anos de idade). Seria necessário tomar medidas para que o aumento da matrícula na universidade não representasse um rebaixamento de nível. Até então nossos alunos entravam na universidade com o que seria, nos Estados Unidos, dois anos de créditos de college em ciências. Por falta de iniciativa e sem jamais assumir o que o IBECC-FUNBEC (que afinal era de fato a USP) havia iniciado, atuando sobre o ensino médio, o nível dos candidatos caiu. A solução não é baixar o nível dos vestibulares: é atuar na escola secundária, inovando.

Enfrentei um problema semelhante em Nova Iorque, quando fui contratado para participar de uma nova experiência de ensino médico no City College cuja meta era produzir o médico de família para a comunidade mais pobre. Para garantir que os médicos prestassem serviços a essa população, foram selecionados candidatos dos grupos étnicos pobres. Os alunos admitidos numa combinação college-curso médico, ao longo de quatro anos, não conseguiam acompanhá-lo. Tentei em vão convencer a direção que era
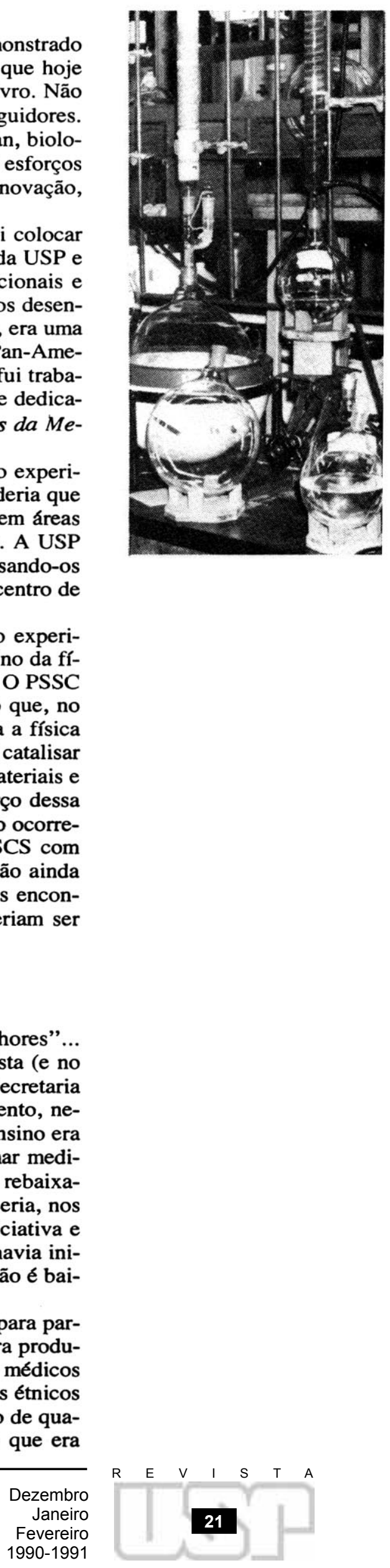
necessário corrigir as deficiências dos estudantes antes do início do curso. A direção achava que os estudantes apenas precisavam de mais tempo para aprender e o curso foise estendendo de quatro, para atingir a sete anos. Os alunos provenientes das minorias jamais conseguiram completá-lo e os alunos que se formavam eram iguais aos das outras escolas médicas: procuravam ser neurocirurgiões ao invés de médicos de famf́lia.

É fundamental entender o que falta para alunos que são culturalmente carentes e como recuperá-los. Não basta aceitá-los na universidade (o seu número é dezenas de vezes maior do que a universidade conseguiria admitir e o custo seria imenso comparado com o custo de reparar o ensino médio). Não sabemos como fazê-lo. Mas é nesta recuperação, onde $\varepsilon$ fundamental ensinar como se aprende, que o computador talvez tenha um papel importante. Para esses estudantes, estudar ciências os amedronta e os repele. Dirigi um projeto que introduziu ciências para alunos de colleges comunitários, destinados a alunos que não pretendem seguir carreiras de nível universitário. Inventamos um curso centrado na análise da dieta de cada estudante (uma preocupação fixa do norte-americano). Cada estudante colhia uma duplicata de tudo o que comia ou bebia durante um dia, levava para o laboratório, passava num liquidificador, secava, e passava um semestre analisando sua comida até quando quisesse. A análise exigia o uso do guia de métodos que era acompanhado por um texto que começava com conceitos muito básicos e elementares, por exemplo, como medir uma porção de objetos circulares - mesas, banquetas, vidros em polegadas e centímetros - para descobrir, por uma simples divisão e por gráfico, que havia uma relação constante entre diâmetro e circunferência, eliminando o pavor por fórmulas matemáticas. O projeto (What people eat) foi um sucesso em nove colleges e foi matéria da capa do Chemical News (provei a mim mesmo que eu era capaz de criar um material didático, agora que não mais contava com os competentes colaboradores que tinha deixado em São Paulo).

Um outro problema básico que não tem sido adequadamente abordado é como permitir ao leigo, qualquer que seja o seu nível cultural, entender como a ciência funciona, como se estabelecem os fatos e, portanto, como funciona um processo de abordagem para problemas e para criticamente avaliar informações recebidas. Não se trata de tentar ensinar isso, mas de fazer com que aprendam, não a passar nos exames, mas a atuar assim no seu dia-a-dia. Aprender adequadamente o desenvolvimento do pensamento cientffico é fundamental para uma visão correta do Universo.

É frustrante descobrir que muitos que atravessaram um curso secundário e, às vezes, universitário são incapazes de discernir um fato cientificamente comprovado de uma superstição ou informação sem fundamento. Mais grave é ainda descobrir que muitos dos nossos alunos de cursos técnico-científicos são capazes de manter uma cultura formal, para uso profissional, ao lado de um comportamento irracional, primitivo, incapaz de analisar fatos. São, portanto, prisioneiros de uma falsa cultura que nos faz duvidar da nossa capacidade de educar. Para citar o que de pior vejo quando vou à biblioteca do Instituto de Química, um dos cientificamente mais produtivos do País, é ver alunos xerocando cadernos de colegas e, nas paredes, anúncios de cursos de homeopatia. As feiras de tarot, o espaço ocupado pelos horóscopos em jornais, lidos pela camada que consideramos educada, são indicadores importantes de como o processo educacional, apesar de permitir a ascensão social e até uma certa competência profissional, tem pouco impacto na formação intelectual de uma sociedade tecnologicamente avançada. A falta de uma atitude cientifica na forma de encarar o Universo leva ao obscurantismo e ao predomínio de formas místicas de controle da sociedade.

Eu creio que este longo passado, ultrapassado e em grande parte esquecido, traz muitas lições. Talvez a mais central é que sem a liderança dos cientistas mais competentes e o envolvimento da universidade em inovar e avaliar o impacto dessas inovações (não do que está á), estaremos desperdiçando o futuro dos nossos jovens e com ele o futuro do País. Ao defender tão ardorosamente o papel da liderança científica, incluo a participação dos educadores que devem estar preocupados com problemas fundamentais da educação e também dos competentes profissionais do ensino de ciências, capazes de traduzir os sonhos dos cientistas em materiais de ensino realmente adequados às nossas escolas e estudantes. Por outro lado, continuo a acreditar na USP, com seu enorme potencial, massa crítica de pensadores e educadores, liderando a inovação em todos os níveis. Essa tarefa, tão importante quanto a pesquisa e a pós-graduação, justifica a universidade que reduzisse sua atividade formal em graduação para transformar-se em um campo experimental de criação de propostas de inovação e sua transferência à rede escolar. 